\title{
A Neurospora crassa mutant altered in the regulation of L-amino acid oxidase
}

\author{
Jorge Calderón, ${ }^{1}$ Leticia Olvera, ${ }^{2}$ Luz María Martínez ${ }^{2}$ \\ and Guillermo Dávila ${ }^{3}$
}

Author for correspondence: Jorge Calderón. Tel: +52 62238 80. Fax: +52 5500048.
e-mail: JFCJ@SERVIDOR.UNAM.MX

1 Departamento de
Biotecnología, Instituto
de Investigaciones
Biomédicas, Universidad
Nacional Autónoma de
México, México DF 04510,
Mexico
2,3 Departamento de
Ecología Molecular ${ }^{2}$ and
Departamento de
Genética Molecular
Centro de Investigación
sobre Fijación de
Nitrógeno UNAM,
Apartado Postal 565-A,
Cuernavaca, Mor., Mexico

The isolation and characterization of a Neurospora crassa mutant altered in Lamino oxidase regulation is reported. The previously isolated g/n-1bR8 strain, which only synthesizes the glutamine synthetase $\alpha$ monomer and lacks the $\beta$ monomer, was used as parental strain. A mutant derivative of strain was selected for its ability to grow on minimal medium in the presence of DLmethionine-SR-sulfoximine (MSO), an inhibitor of glutamine synthetase activity. This gln-1bR8; MSOR mutant overcame the inhibitory effect of MSO by increasing the activity of L-amino acid oxidase, an enzyme capable of degrading this compound. In contrast with the wild-type strain, the L-amino acid oxidase of the $M S O^{R}$ mutant was resistant to glutamine repression; in fact, it was induced by this amino acid but repressed by ammonium. This mutant is different from other nitrogen regulatory $\boldsymbol{N}$. crassa mutants reported and is only altered in the regulation of L-amino acid oxidase. The MSO ${ }^{R}$ mutation is epistatic to nit-2 since the nit2; $M S O^{R}$ double mutant regulated the L-amino acid oxidase in the same way as the $M S O^{R}$ single mutant.

Keywords: L-amino acid oxidase, Neurospora crassa, regulation, nitrogen metabolism

\section{INTRODUCTION}

In Neurospora crassa, there are different nitrogen catabolic pathways which are hierarchically governed to ensure a constant nitrogen supply for growth, even in the face of widely different or rapidly changing environments. Thus, N. crassa favours readily metabolizable nitrogen sources such as ammonium, glutamate and glutamine (primary sources), but can use a variety of secondary sources such as nitrate, purines, proteins, peptides, amino acids and amides when the primary sources are limited (Marzluf, 1993). The process of nitrogen metabolite repression ensures that the systems for utilization of secondary nitrogen sources are inactive in the presence of a primary nitrogen source. Such repression is believed to be glutamine-mediated, with ammonium and glutamate also showing repression since they are precursors of glutamine (Marzluf, 1981). In most cases, turning on the expression of a particular nitrogen catabolic pathway requires two distinct signals, one that is global and indicates nitrogen limitation and a second, pathway-specific, signal (Marzluf, 1993).

Abbreviations: LAO, L-amino acid oxidase; MSO, DL-methionine-SRsulfoximine.
In $N$. crassa, NIT2 is the positive regulatory protein required for expression of genes involved in the utilization of secondary nitrogen sources and in ammonium assimilation enzymes (glutamine synthetase and glutamate dehydrogenase) when the cells are subject to nitrogen limitation (Marzluf, 1981, 1993; Calderón \& Martínez, 1993). NIT2 is a protein of 1036 amino acid residues with a single zinc domain that functions as a site-specific DNA-binding protein ( $\mathrm{Fu} \&$ Marzluf, 1990a, b).

In $N$. crassa, two allelic mutant strains have been isolated (nmr-1 and $m s-5)$ which fail to respond to nitrogen catabolic repression (Dunn-Coleman et al., 1981; Premakumar et al., 1980). nmr is unlinked to nit2 and appears to act in a negative fashion to repress the synthesis of nitrate reductase and other nitrogen catabolic enzymes and ammonium assimilation enzymes (Dunn-Coleman et al., 1981; Sikora \& Marzluf, 1982; DeBusk \& Ogilvie, 1984b; Calderón \& Martínez, 1993). The $n m r$ gene has been cloned and shown to be expressed constitutively (Fu et al., 1988). NMR does not appear to have any DNA-binding activity nor to directly inhibit the transcription of nit-2 or the nitrogencontrolled structural genes (Xiao et al., 1995). A direct interaction between NIT2 and the NMR protein has 
been demonstrated and the NMR protein inhibits NIT2 INA binding (Xiao et al., 1995). It has been suggested that NMR carries out its negative regulatory role by directly binding to NIT2, thereby blocking the function of NIT2 by inhibiting DNA-binding activity (Xiao et al., 1995).

In $N$. crassa the first step in the catabolism of many amino acids is an oxidative deamination, yielding the corresponding 2-oxo acid and ammonium, catalysed by I-amino acid oxidase (LAO; EC 1.4.3.2) (Sikora \& Marzluf, 1982). LAO is present in both cell extracts and the growth medium; biotin-limited medium enhances I.AO levels and significant amounts of LAO are present in cultures undergoing sexual differentiation (Thayer $\&$ Horowitz, 1951; Horowitz, 1965). LAO is synthesized by $N$. crassa following addition of L-amino acids to nitrogen-starved cultures as well as upon addition of protein synthesis inhibitors or D-amino acids (Sikora \& Marzluf, 1982; Neiderman \& Lerch, 1991). LAO mRNA levels increase rapidly in response to the inducing agents, indicating that the LAO gene is regulated at the transcriptional level (Neiderman \& Lerch, 1991). The expression of LAO is controlled by NIT2; thus, nit-2 mutants are repressed for LAO activity under conditions which lead to good enzyme induction in the wild-type (Sikora \& Marzluf, 1982; DeBusk \& Ogilvie, 1984a). At least two NIT2-binding sites have been found in the promoter region of LAO gene (Xiao \& Marzluf, 1993). The expression of LAO is also controlled by the $n m r$ gene product; thus LAO is insensitive to nitrogen metabolic repression in the $n m r-1$ or $m s-5$ mutants (Chambers et al., 1983; DeBusk \& Ogilvie, 1984b).

In this work, we describe the isolation and characterization of an $N$. crassa mutant altered in the regulation of LAO.

\section{METHODS}

Strains. All the N. crassa strains came either from the collection of J. Mora, Centro de Investigación sobre Fijación de Nitrógeno, Cuernavaca, Morelos, Mexico, or from the Fungal Genetic Stock Center, Kansas City, KS, USA. The basic stocks were the 74- $A$ and $73-a$ wild-type strains, the nit- 2 and $m s-5$ regulatory mutant strains (Coddington, 1976; Premakumar et al., 1980) and the gln-1bR8 mutant strain, which lacks the glutamine synthetase $\beta$ monomer (Dávila et al., 1983).

Growth conditions. Batch cultures of N. crassa were grown at $30{ }^{\circ} \mathrm{C}$ with shaking (250 r.p.m.) on Vogel minimal medium (Vogel, 1956) supplemented with $1.5 \%(\mathrm{w} / \mathrm{v})$ sucrose. In some experiments, the carbon and nitrogen source were substituted as stated in the text. The conidia used as inoculum were harvested from slants of Vogel medium supplemented with $1.5 \%(\mathrm{w} / \mathrm{v})$ sucrose, which had been grown in the dark for $3 \mathrm{~d}$ at $29^{\circ} \mathrm{C}$, followed by $2 \mathrm{~d}$ under incandescent light at $25^{\circ} \mathrm{C}$.

Determination of enzyme activities. Cell-free extracts were prepared as described previously (Dávila et al., 1978). LAO activity was monitored by following the appearance of ketoacid according to Sikora \& Marzluf (1982). Glutamine synthetase was measured as described by Ferguson $\&$ Sims (1974). Nitrate reductase was assayed as described by Sorger et al. (1974).
Mutant selection. A suspension of conidia of the $g \ln -1 b R 8$ mutant strain in distilled water was plated on Vogel minimal medium supplemented with glucose and fructose $(0.02 \%$ each), sorbose $(2 \%)$, and $5 \mathrm{mM}$ DL-methionine-SRsulfoximine (MSO). Plates were incubated at $29^{\circ} \mathrm{C}$ in the dark until colonies appeared (2-3 d) and then transferred to slants of Vogel minimal medium supplemented with $1.5 \%$ sucrose. Crosses were made on Westergaard synthetic crossing medium (Westergaard \& Mitchell, 1947) as described by Davis \& Serres (1970). Spot testing and progeny analysis were also carried out as described by Davis \& Serres (1970).

Determination of amino acid pools. Samples were prepared as described elsewhere (Calderón \& Martínez, 1993). Amino acids were separated with an Aminco amino acid analyser and quantified in an Aminco ratio fluorimeter after coupling with $o$-phthaldialdehyde.

Protein determination. Samples of mycelia were prepared as described elsewhere (Calderón \& Martínez, 1993). Protein was determined by the Lowry method, using bovine serum albumin as a standard.

Reproducibility of results. The experiments reported were each repeated at least once; representative results are shown.

\section{RESULTS}

\section{Isolation of the $g / n-1 b R 8 ; M S O^{R}$ mutant}

In N. crassa, the inhibitor of glutamine synthetase MSO is degraded by LAO and by glutamine transaminase (Calderón et al., 1990). To select mutants altered in LAO regulation, we started with a parental strain $(\mathrm{g} \ln$ $1 b R 8$ ) that lacks the glutamine synthetase $\beta$ polypeptide and is therefore more sensitive to growth inhibition by MSO than the wild-type (Dávila, 1983). Spontaneous mutants of $g \ln -1 b R 8$ resistant to MSO growth inhibition were selected for their ability to grow on $25 \mathrm{mM}$ $\mathrm{NH}_{4} \mathrm{NO}_{3}$ as nitrogen source plus $5 \mathrm{mM}$ MSO. Three of these $g \ln -1 b R 8 ; M S O^{\mathrm{R}}$ mutant strains were purified by crosses with the $g \ln -1 b R 8$ strain and further characterized. These three mutants were altered in LAO regulation in a similar way, although the mutant described here had the greatest alteration in the regulation of this enzyme.

\section{Growth, glutamate content, and glutamine synthetase, LAO and glutamine transaminase activities}

The $g \ln -1 b R 8 ; M S O^{\mathrm{R}}$ mutant grew similarly on $\mathrm{NH}_{4} \mathrm{NO}_{3}$ as the nitrogen source in the presence or absence of MSO, whereas the parental $g \ln -16 \mathrm{R} 8$ strain did not grow at all in the presence of MSO (Fig. 1). The $g \ln -1 b R 8 ; M S O^{\mathrm{R}}$ mutant was also able to use MSO as a sole nitrogen source, whereas the parental $g \ln -1 b R 8$ strain did not grow (Fig. 1). The $g \ln -1 b R 8$ and the $g \ln$ $1 b R 8 ; M S O^{\mathrm{R}}$ strains grew similarly on $\mathrm{NH}_{4} \mathrm{NO}_{3}$ as nitrogen source in the absence of MSO (Fig. 1). The fact that the $g \ln -1 b R 8 ; M S O^{\mathrm{R}}$ mutant grows on $\mathrm{MSO}$ as nitrogen source indicates that, in this mutant, MSO is degraded efficiently.

Since MSO inhibits glutamine synthetase and therefore prevents glutamine synthesis from glutamate and am- 


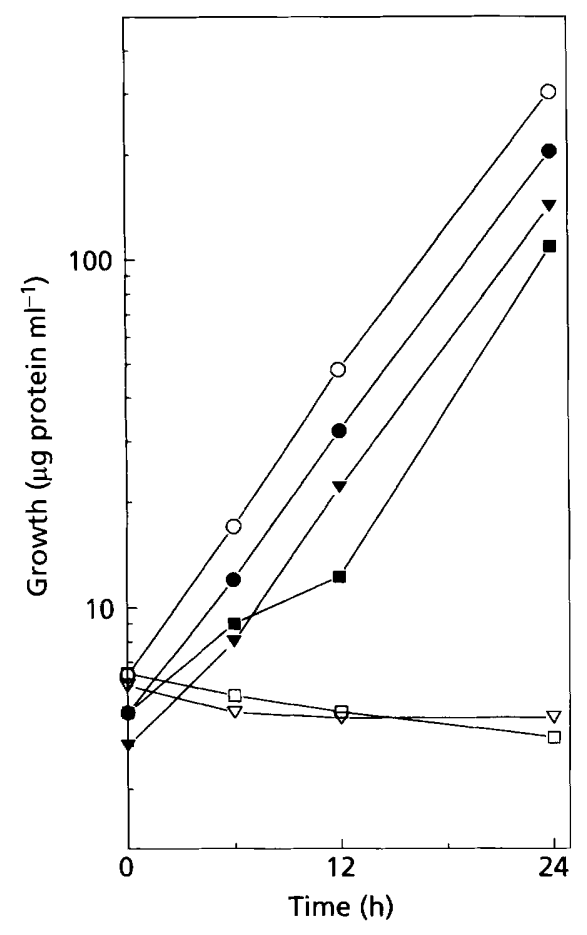

Fig. 1. Growth curves of the parental g/n-1bR8 strain (open symbols) and the g/n-1bR8;MSOR mutant (filled symbols) on: $25 \mathrm{mM} \mathrm{NH}_{4} \mathrm{NO}_{3}(0,0), 25 \mathrm{mM} \mathrm{NH}_{4} \mathrm{NO}_{3}$ plus $5 \mathrm{mM} \mathrm{MSO}(\nabla, \nabla)$, and $5 \mathrm{mM}$ MSO $([, \boldsymbol{\square})$.

monium, we measured the intracellular glutamate pools in the $g \ln -1 b R 8 ; M S O^{\mathrm{R}}$ mutant under different growth conditions. In comparison with the $g \ln -1 b R 8$ strain, the $g \ln$-1bR $8 ; M S O^{\mathrm{R}}$ mutant showed a 12-fold lower glutamate content when grown on $\mathrm{NH}_{4} \mathrm{NO}_{3}$ as nitrogen source in the presence of MSO [9.7 vs $0.8 \mu \mathrm{mol}(\mathrm{mg}$ protein $)^{-1}$, a 27 -fold lower glutamate content when grown on MSO as nitrogen source [5.4 vs $0.2 \mu \mathrm{mol}(\mathrm{mg}$ protein $\left.)^{-1}\right]$ and similar glutamate content when grown on $\mathrm{NH}_{4} \mathrm{NO}_{3}$ as nitrogen source $[0.3$ vs $0.4 \mu \mathrm{mol}$ (mg protein $\left.)^{-1}\right]$. These results indicate that, in the gln$1 b R 8 ; M S O^{\mathrm{R}}$ mutant, glutamine synthetase is not being inhibited by MSO.

To determine if glutamine synthetase was altered in the gln-1bR $8 ; M S O^{\mathrm{R}}$ mutant we measured its activity and the inhibitory effect of MSO on this enzyme in cell extracts of this mutant. The $g \ln -1 b R 8 ; M S O^{\mathrm{R}}$ and $g \ln$ $1 b R 8$ strains had similar glutamine synthetase activity under the different conditions tested and the glutamine synthetase activity of both strains was inhibited by MSO in similar ways (data not shown).

Since we did not find any alterations in glutamine synthetase in the $g \ln -1 b R 8 ; M S O^{\mathrm{R}}$ mutant, the failure of MSO to inhibit mutant growth could have been due to the compound being degraded. To investigate this possibility, we measured the LAO and the glutamine transaminase activities in the $g \ln -1 b R 8 ; M S O^{\mathrm{R}}$ mutant under different growth conditions. In comparison with the $g \ln -1 b R 8$ strain, the $g \ln -1 b R 8 ; M S O^{\mathrm{R}}$ strain had higher LAO activity: 13-fold higher on $\mathrm{NH}_{4} \mathrm{NO}_{3}$ as nitrogen source $\left[1.0 \mathrm{vs} 13.4 \mathrm{nmol} 2\right.$-oxo-acid $\mathrm{min}^{-1}$ (mg protein $)^{-1}$ ], 16-fold higher on $\mathrm{NH}_{4} \mathrm{NO}_{3}$ as nitrogen source in the presence of MSO $[<1.0$ vs $16.5 \mathrm{nmol} 2$ oxo-acid $\min ^{-1}$ (mg protein $\left.)^{-1}\right]$, and 78 -fold higher on MSO as nitrogen source $[<1.0$ vs $78.3 \mathrm{nmol} 2$-oxo-acid $\min ^{-1}$ (mg protein $\left.)^{-1}\right]$. The glutamine transaminase activity of the $g \ln -1 b R 8 ; M S O^{\mathrm{R}}$ mutant was similar to that of the $g \ln -1 b R 8$ strain under the different conditions tested (data not shown). These results indicate that the $g \ln -1 b R 8 ; M S \mathrm{O}^{\mathrm{R}}$ mutant overcame the inhibitory effect of MSO by degrading this compound, through an increase in LAO activity.

\section{Growth tests and nitrate reductase}

In an attempt to test whether the derepression of LAO exhibited by the $g \ln -1 b R 8 ; M S O^{\mathrm{R}}$ double mutant was a specific or a general response, we compared the growth characteristics of this mutant and an $M S O^{\mathrm{R}}$ single

Table 1. Growth tests of wild-type, mutants $g / n-1 b R 8, g / n-1 b R 8 ; M S O^{R}$ and $M S O^{R}$, and the regulatory mutants nit- $2, \mathrm{~ms}-5$ and nit-2;MSOR

++ , Strong growth; + , growth; - , no growth. Supplement concentrations were: $10 \mathrm{mM}$ $\mathrm{NH}_{4} \mathrm{NO}_{3}$ and $\mathrm{KNO}_{3}, 5 \mathrm{mM}$ glutamine and $\mathrm{MSO}$, and $100 \mathrm{mM} \mathrm{KClO}_{3}$.

\begin{tabular}{|c|c|c|c|c|c|c|}
\hline \multirow[t]{2}{*}{ Strain } & \multicolumn{6}{|c|}{ Growth conditions: } \\
\hline & $\mathrm{NH}_{4} \mathrm{NO}_{3}$ & $\begin{array}{c}\mathrm{NH}_{4} \mathrm{NO}_{3} \\
\text { plus } \mathrm{MSO}\end{array}$ & $\begin{array}{c}\mathrm{NH}_{4} \mathrm{NO}_{3} \\
\text { plus } \mathrm{KClO}_{3}\end{array}$ & $\mathrm{KNO}_{3}$ & Glutamine & $\begin{array}{c}\text { Glutamine } \\
\text { plus } \mathrm{KClO}_{3}\end{array}$ \\
\hline Wild-type & ++ & + & ++ & ++ & ++ & ++ \\
\hline$g \ln -1 b R 8$ & + & - & + & + & ++ & ++ \\
\hline$g \ln -1 b R 8 ; M S O^{\mathbf{R}}$ & + & + & + & + & ++ & ++ \\
\hline$M S O^{R}$ & ++ & ++ & ++ & ++ & ++ & ++ \\
\hline nit-2 & ++ & - & ++ & - & ++ & ++ \\
\hline$m s-5$ & ++ & ++ & - & ++ & ++ & - \\
\hline nit-2;MSO ${ }^{\mathrm{R}}$ & ++ & ++ & ++ & - & ++ & ++ \\
\hline
\end{tabular}


Table 2. LAO activity of wild-type, g/n-1bR8, nit-2, g/n$1 b R 8 ; M S O^{R}, M S O^{R}$ and nit-2;MSO ${ }^{R}$ strains grown under different conditions

The activities were measured after $24 \mathrm{~h}$ of growth and are expressed as nmol 2-oxo-acid $\min ^{-1}$ (mg protein) $)^{-1}$. The numbers in parentheses represent standard deviations of three determinations.

\begin{tabular}{|c|c|c|c|}
\hline \multirow[t]{2}{*}{ Strain } & \multicolumn{3}{|c|}{ Growth conditions } \\
\hline & $\begin{array}{c}\mathrm{NH}_{4} \mathrm{NO}_{3}, \\
25 \mathrm{mM}\end{array}$ & $\begin{array}{c}\mathrm{NH}_{4} \mathrm{NO}_{3 "} \\
2 \mathrm{mM}\end{array}$ & $\begin{array}{l}\text { Glutamine } \\
5 \mathrm{mM}\end{array}$ \\
\hline Wild-type & $0 \cdot 8(0 \cdot 2)$ & $8 \cdot 5(2)$ & $1.6(0.3)$ \\
\hline$g \ln -1 b R 8$ & $1 \cdot 0(0 \cdot 2)$ & $8 \cdot 3(2)$ & $1 \cdot 3(0 \cdot 2)$ \\
\hline nit-2 & $1 \cdot 3(0 \cdot 2)$ & $3 \cdot 0(0 \cdot 5)$ & $1 \cdot 7(0 \cdot 3)$ \\
\hline$g \ln -1 b R 8 ; M S O^{\mathrm{R}}$ & $13 \cdot 4(2)$ & $50 \cdot 6(8)$ & $25 \cdot 0(4)$ \\
\hline$M S O^{\mathrm{R}}$ & $1 \cdot 1(0 \cdot 2)$ & $74.5(9)$ & $42 \cdot 0(6)$ \\
\hline nit-2;MSO $\mathrm{O}^{\mathrm{R}}$ & $0 \cdot 8(0 \cdot 2)$ & $65.6(7)$ & $34 \cdot 2(5)$ \\
\hline
\end{tabular}

mutant with those of the general nitrogen regulatory mutants $m s-5$ and nit-2 (see Methods). The $M S O^{\mathrm{R}}$ single mutant was obtained by crosses between the $g l n$ $1 b R 8 ; M_{S O} O^{\mathrm{R}}$ mutant and the wild-type strain. The $M S O^{\mathrm{R}}$ mutant grew as well as the wild-type on $\mathrm{NH}_{4} \mathrm{NO}_{3}$ and was more resistant to MSO inhibition (Table 1). In comparison with the wild-type, the nit-2 mutant was more sensitive to MSO inhibition whereas the $m s-5$ mutant was more resistant. The $g \ln -1 b R 8 ; M S O^{\mathrm{R}}$ and $\mathrm{MSO}^{\mathrm{R}}$ strains were resistant to chlorate inhibition in contrast with the $m s-5$ mutant, which was sensitive. Chlorate, an analogue of nitrate, is thought to be rendered toxic by nitrate reductase due to the formation of chlorite. Wild-type N. crassa is sensitive to chlorate under nonrepressing conditions but becomes resistant when ammonium, glutamate or glutamine is present in the medium. Mutants derepressed for nitrate reductase, like the $m s-5$ mutant, are thus sensitive to chlorate under conditions which repress nitrate reductase in the wildtype strain (Dunn-Coleman et al., 1979). These results indicate that the $g \ln -1 b R 8 ; M_{S O}^{\mathrm{R}}$ and $M S O^{\mathrm{R}}$ strains are not derepressed for nitrate reductase regulation. Since the nit-2 mutant is altered in the global positiveacting protein that activates LAO, we obtained a nit$2 ; M S O^{\mathrm{R}}$ double mutant to determine whether the $M S O^{\mathrm{R}}$ mutation is epistatic to nit-2. We found that nit$2 ; \mathrm{MSO}^{\mathrm{R}}$ was resistant to $\mathrm{MSO}$, in contrast with the nit2 mutant, which was sensitive (Table 1).

Nitrate reductase activity was also measured to determine whether the altered regulation of LAO in the $g \ln -1 b R 8 ; M S O^{\mathrm{R}}$ mutant was a specific or a general response since this enzyme is regulated by the general mechanism of nitrogen metabolite repression, as is LAO (Marzluf, 1993). In comparison with the $g \ln -1 b R 8$ strain, the $g \ln -1 b R 8 ; M S O^{\mathrm{R}}$ strain had a similar nitrate reductase activity under the different conditions tested (data not shown).
Table 3. LAO activity of the wild-type and the $M S O^{R}$ single mutant grown under different conditions

Activities are expressed as nmol 2-oxo-acid $\min ^{-1}(\mathrm{mg}$ protein $)^{-1}$. Glutamine concentration was $5 \mathrm{mM}$. The numbers in parentheses represent standard deviations of three determinations.

\begin{tabular}{|lcc|}
\hline Growth conditions & \multicolumn{2}{c|}{ Strain } \\
\cline { 2 - 3 } & Wild-type & MSO \\
\hline Glutamine* & $2 \cdot 0(0 \cdot 4)$ & $48 \cdot 3(8)$ \\
Glutamine† & $1 \cdot 6(0 \cdot 3)$ & $42 \cdot 0(6)$ \\
Glutamine plus $25 \mathrm{mM} \mathrm{NH}_{4} \mathrm{NO}_{3} \dagger$ & $0 \cdot 3(0 \cdot 2)$ & $5 \cdot 3(1)$ \\
Glutamine; after 12 h growth, & $0 \cdot 5(0 \cdot 2)$ & $3 \cdot 2(0 \cdot 6)$ \\
$\mathrm{NH}_{4} \mathrm{NO}_{3}$ added to $25 \mathrm{mM} \dagger$ & & \\
\hline
\end{tabular}

* Activities were measured after $12 \mathrm{~h}$ growth.

† Activities were measured after $24 \mathrm{~h}$ growth.

\section{LAO regulation in the $M S O^{R}$ mutant}

The wild-type and the $g \ln -1 b R 8$ strains had similar LAO activity under the different conditions tested; these strains had sevenfold higher LAO activity on $2 \mathrm{mM}$ $\mathrm{NH}_{4} \mathrm{NO}_{3}$ as nitrogen source than on $25 \mathrm{mM} \mathrm{NH} \mathrm{NO}_{3}$ or on glutamine as nitrogen source (Table 2). In comparison with the $g \ln -1 b R 8$ strain, the $g \ln$ $1 b R 8 ; M S O^{\mathrm{R}}$ had sixfold higher LAO activity on $2 \mathrm{mM}$ $\mathrm{NH}_{4} \mathrm{NO}_{3}$ as nitrogen source and 19-fold higher LAO activity on glutamine as nitrogen source (Table 2). In contrast with the $g \ln -1 b R 8 ; M S O^{\mathbf{R}}$ double mutant, the $M S \mathrm{O}^{\mathrm{R}}$ single mutant had lower LAO activity on $25 \mathrm{mM}$ $\mathrm{NH}_{4} \mathrm{NO}_{3}$ as nitrogen source but slightly higher LAO activity on $2 \mathrm{mM} \mathrm{NH} \mathrm{NH}_{4} \mathrm{NO}_{3}$ or on glutamine as nitrogen source (Table 2).

Since the $M S O^{\mathrm{R}}$ mutant is derepressed for LAO in some media, we determined whether the $M S O^{\mathrm{R}}$ mutation was epistatic to nit-2. The nit-2 strain had similar LAO activity on $25 \mathrm{mM} \mathrm{NH}_{4} \mathrm{NO}_{3}$ or on glutamine as nitrogen source as did the wild-type, but it had threefold lower LAO activity on $2 \mathrm{mM} \mathrm{NH} \mathrm{NO}_{3}$ as nitrogen source. The nit-2;MSO ${ }^{\mathrm{R}}$ double mutant had slightly lower LAO activity than the $M S O^{\mathrm{R}}$ single mutant under the different conditions tested (Table 2).

Since the $M S O^{\mathrm{R}}$ single mutant is derepressed for LAO activity on glutamine as nitrogen source but not on $25 \mathrm{mM} \mathrm{NH} \mathrm{NO}_{3}$ as nitrogen source, we determined whether $\mathrm{NH}_{4} \mathrm{NO}_{3}$ was able to repress LAO in the presence of glutamine in this mutant. As shown in Table 3 , the $M S \mathrm{O}^{\mathrm{R}}$ mutant on $25 \mathrm{mM} \mathrm{NH} \mathrm{NO}_{3}$ plus glutamine as nitrogen source had eightfold lower LAO activity than on glutamine alone as nitrogen source. Moreover, the LAO activity determined after $24 \mathrm{~h}$ growth diminished about 13-fold when $\mathrm{NH}_{4} \mathrm{NO}_{3}$ was added to the culture medium to obtain a concentration of $25 \mathrm{mM}$ after $12 \mathrm{~h}$ growth on glutamine as nitrogen source. 
Table 4. LAO activity of the wild-type and the $M S O^{R}$ single mutant grown with different amino acids as nitrogen source

Activities were measured after $24 \mathrm{~h}$ of growth and expressed as nmol 2-oxo-acid $\min ^{-1}$ (mg protein) ${ }^{-1}$. Amino acid

concentration was $5 \mathrm{mM}$. The numbers in parentheses represent standard deviations of three determinations.

\begin{tabular}{|c|c|c|}
\hline \multirow[t]{2}{*}{ Amino acid } & \multicolumn{2}{|c|}{ Strain } \\
\hline & Wild-type & $M S O^{\mathrm{R}}$ \\
\hline Arginine & $1 \cdot 1 \quad(0 \cdot 2)$ & $43 \cdot 2 \quad(7)$ \\
\hline Asparagine & $1.9 \quad(0 \cdot 4)$ & $54 \cdot 6 \quad\langle 8\rangle$ \\
\hline Glutamate & $2.6 \quad(0.5)$ & $109 \cdot 5(15)$ \\
\hline Aspartate & $9 \cdot 6 \quad(2)$ & $68.6 \quad(8)$ \\
\hline Alanine & $14 \cdot 3 \quad(2)$ & $87 \cdot 47(15)$ \\
\hline Proline & $14 \cdot 6 \quad(2)$ & $237 \cdot 7(25)$ \\
\hline Norleucine & $21 \cdot 8 \quad(3)$ & $149 \cdot 4(20)$ \\
\hline Ornithine & $24 \cdot 3 \quad(3)$ & $99 \cdot 5(15)$ \\
\hline Leucine & $30 \cdot 0$ & $64 \cdot 5 \quad(8)$ \\
\hline Isoleucine & $34.7 \quad(6)$ & $197 \cdot 2(25)$ \\
\hline Methionine & $35.6 \quad(6)$ & $102 \cdot 5(15)$ \\
\hline Phenylalanine & $50 \cdot 2 \quad(8)$ & $131 \cdot 7(20)$ \\
\hline Lysine & $56 \cdot 4 \quad(8)$ & $92 \cdot 4(15)$ \\
\hline Valine & $68 \cdot 7(10)$ & $243 \cdot 2(30)$ \\
\hline Glycine & $188 \cdot 3(25)$ & $342 \cdot 9(40)$ \\
\hline Histidine & $210 \cdot 0\langle 25\rangle$ & $326 \cdot 0(40)$ \\
\hline
\end{tabular}

We also measured LAO activity of the $M S O^{\mathrm{R}}$ mutant grown on different amino acids as nitrogen source to determine whether the LAO activity of this mutant was altered when other amino acids besides glutamine were used as nitrogen source. In comparison with the wildtype strain, the $M S O^{\mathrm{R}}$ mutant had higher LAO activity with the different amino acids tested, e.g. 42-fold higher on glutamate as nitrogen source, 39-fold higher on arginine as nitrogen source and 29-fold higher on asparagine as nitrogen source (Table 4).

\section{DISCUSSION}

The $g \ln -1 b R 8 ; M S O^{\mathrm{R}}$ mutant was selected for its ability to grow on $\mathrm{NH}_{4} \mathrm{NO}_{3}$ as nitrogen source plus the inhibitor of glutamine synthetase MSO. We started with a parental strain $(g \ln -1 b R 8)$ that lacks the glutamine synthetase $\beta$ polypeptide and is more sensitive to growth inhibition by MSO than the wild-type strain (Dávila, 1983). The $g \ln -1 b R 8 ; M S O^{\mathrm{R}}$ mutant grows on MSO as nitrogen source indicating that, in this mutant, this compound is degraded efficiently.

The facts that the $g \ln -1 b R 8 ; M S O^{\mathrm{R}}$ mutant had a higher LAO activity than the $g \ln -1 b R 8$ strain when grown on the presence of MSO, that glutamine synthetase and glutamine transaminase were not altered in this mutant, and that it had a lower glutamate content than its parent when grown in the presence of MSO, indicate that the $g \ln -1 b R 8 ; M S O^{\mathrm{R}}$ mutant overcame the inhibitory effect of MSO by degrading this compound, through an increase in LAO activity.

Growth characteristics of the $g \ln -1 b R 8 ; M S O^{\mathrm{R}}$ mutant, and the fact that nitrate reductase is not derepressed for nitrate reductase, indicate that the derepression of LAO exhibited by the $M S O^{\mathrm{R}}$ mutant is restricted to LAO, in contrast with the general nitrogen regulatory mutant ms-5 (Premakumar et al., 1980; Chambers et al., 1983; DeBusk \& Ogilvie, 1984b). The $M S O^{\mathrm{R}}$ mutation was epistatic to nit-2 since the nit $2 ; M S O^{\mathrm{R}}$ double mutant is resistant to MSO and regulates $\mathrm{LAO}$ in the same way as the $M S O^{\mathrm{R}}$ single mutant.

It is interesting that the $M S O^{\mathrm{R}}$ mutant has lost the repression of LAO by glutamine and its dependence on the global positive-acting regulatory protein NIT2 that has been shown to control LAO expression ( Fu \& Marzluf, 1990a). We propose that the $M S^{\mathrm{R}}$ mutant has a mutation that disrupts the binding site of NIT2 so that the LAO gene is transcribed by another promoter. Since it has been demonstrated that NMR, the putative negative-acting regulator that mediates nitrogen repression, binds to NIT2 we could speculate that a NIT2-NMR complex bound at the binding site of NIT2 might function as a repressor. This could explain the simultaneous loss of repression by glutamine and of NIT2 activation by the $M S O^{\mathrm{R}}$ mutant. Nevertheless, against this proposal are the results of mobility-shift experiments by Xiao et al. (1995), which revealed that the NMR protein inhibits DNA binding in vitro. Also, it is interesting that the $M S O^{\mathrm{R}}$ single mutant is derepressed for LAO activity on glutamine as nitrogen source but not on $25 \mathrm{mM} \mathrm{NH} \mathrm{NO}_{3}$, since the $n m r-1$ and $m s-5$ regulatory mutants lose the repression for some enzymes of the nitrogen metabolism in the presence of ammonium and glutamine. Therefore, since the promoter which functions for the transcription of LAO in the $M S \mathrm{O}^{\mathrm{R}}$ mutant is regulated by ammonium but not by glutamine, we propose that the signal could be related to carbon metabolism rather than to ammonium. With an excess of ammonium there is a high flux of carbon catabolism due to the assimilation of ammonium that consumes carbon skeletons, energy and NADPH. In contrast, under conditions of ammonium limitation or on a poor nitrogen source the demand for carbon skeletons is lower.

\section{ACKNOWLEDGEMENTS}

We are grateful to Jaime Mora for his encouragement and discussion throughout this work, to Gisela Du Pont for amino acid determinations and to Isabel Pérez Montfort for critical review of the manuscript.

This work was supported by DGAPA Grant IN200996 from the Universidad Nacional Autónoma de México.

\section{REFERENCES}

Calderón, J. \& Martínez, L. M. (1993). Regulation of ammonium ion assimilation enzymes in Neurospora crassa nit-2 and $m s-5$ mutant strains. Biochem Genet 31, 425-439. 
Calderón, J., Martínez, L. M. \& Mora, J. (1990). Isolation and characterization of a Neurospora crassa mutant altered in the $\alpha$ polypeptide of glutamine synthetase. J Bacteriol 172, 4996-5000.

Chambers, J. A. A., Griffon, S. M. \& Marzluf, G. A. (1983). Transnuclear action of the nut-2 regulatory gene product and study of two additional nitrogen control genes in Neurospora crassa. Curr Genet 7, 51-56.

Coddington, A. (1976). Biochemical studies on the nit mutants of Neurospora crassa. Mol Gen Genet 145, 195-206.

Dávila, G., Brom, S., Mora, Y., Palacios, R. \& Mora, J. (1983). Genetic and biochemical characterization of glutamine synthetase from Neurospora crassa auxotrophs and their revertants. $J$ Bacteriol 156, 993-1000.

Davis, R. H. \& De Serres, F. J. (1970). Genetic and microbiological research technique for Neurospora crassa. Methods Enzymol 17, 79-143.

DeBusk, R. M. \& Ogilvie, S. (1984a). Nitrogen regulation of amino acid utilization by Neurospora crassa. J Bacteriol 160, 493-498.

DeBusk, R. M. \& Ogilvie, S. (1984b). Regulation of amino acid utilization in Neurospora crassa: effect of $n m r-1$ and $m s-5$ mutations. J Bacteriol 160, 656-661.

Dunn-Coleman, N. S., Tomsett, A. B. \& Garret, R. H. (1979). Nitrogen metabolite repression of nitrate reductase in Neurospora crassa: effect of the gln-1a locus. J Bacteriol 139, 697-700.

Dunn-Coleman, N. S., Tomsett, A. B. \& Garret, R. H. (1981). The regulation of nitrate assimilation in Neurospora crassa: biochemical analysis of the $n m r-1$ mutants. Mol Gen Genet 182, 234-239.

Fu, Y. H. \& Marzluf, G. A. (1990a). nit-2, the major nitrogen regulatory gene of Neurospora crassa, encodes a protein with a putative zinc finger DNA-binding domain. Mol Cell Biol 10, 1056-1065.

Fu, Y. H. \& Marzluf, G. A. (1990b). nit-2, the major positive-acting nitrogen regulatory gene of Neurospora crassa, encodes a sequence specific DNA-binding protein. Proc Natl Acad Sci USA 87, 5331-5335.

Fu, Y. H., Young, J. L. \& Marzluf, G. A. (1988). Molecular cloning and characterization of a negative-acting nitrogen regulatory gene of Neurospora crassa. Mol Gen Genet 214, 74-79.
Horowitz, N. H. (1965). Evidence for common control of tyrosinase and L-amino acid oxidase in Neurospora. Biochem Biophys Res Commun 18, 686-692.

Marzluf, G. A. (1981). Regulation of nitrogen metabolism and gene expression in fungi. Micrbiol Rev 45, 437-461.

Marzluf, G. A. (1993). Regulation of sulfur and nitrogen metabolism in filamentous fungi. Annu Rev Microbiol 47, 31-55.

Neidermann, D. M. \& Lerch, K. (1991). Regulation of biosynthesis of L-amino acid oxidase by Neurospora crassa. FEMS Microbiol Lett 79, 309-314.

Premakumar, R., Sorger, G. J. \& Goodman, D. (1980). Physiological characterization of a Neurospora crassa mutant with impaired regulation of nitrate reductase. J Bacteriol 144, 542-551.

Sikora, L. \& Marzluf, G. A. (1982). Regulation of L-amino acid oxidase and D-amino acid oxidase in Neurospora crassa. Mol Gen Genet 186, 33-39.

Sorger, G. J., Debanne, M. T. \& Davis, J. (1974). Effect of nitrate on the synthesis and decay of nitrate reductase in Neurospora. Biochem J 140, 395-403.

Thayer, P. S. \& Horowitz, N. H. (1951). The L-amino oxidase of Neurospora. J Biol Chem 192, 755-767.

Vogel, H. J. (1956). A convenient growth medium for Neurospora crassa (medium N). Microb Genet Bull 13, 42-43.

Westergaard, M. \& Mitchell, H. K. (1947). Neurospora V: a synthetic medium favoring sexual production. Am $J$ Bot 34, 573-574.

Xiao, X. D., Fu, Y. H. \& Marzluf, G. A. (1995). The negative-acting NMR regulatory protein of Neurospora crassa binds to and inhibits the DNA-binding activity of the positive-acting nitrogen regulatory protein NIT2. Biochemistry 34, 8861-8868.

Xiao, X. D. \& Marzluf, G. A. (1993). Amino-acid substitutions in the zinc finger of NIT2, the nitrogen regulatory protein of Neurospora crassa alter promoter element recognition. Curr Genet 24, 212-218.

Received 17 December 1996; revised 3 February 1997; accepted 6 February 1997. 